5.

Derecho administrativo 

Revista de Derecho

de la Pontificia Universidad Católica de Valparaíso

XL (Valparaíso, Chile, 2013, ${ }^{\text {er }}$ Semestre)

[pp. 421 - 447]

\title{
Fundamento y LÍMITES DE LA POTESTAD \\ SANCIONADORA ADMINISTRATIVA EN MATERIA AMBIENTAL
}

[Grounds for and Limits of the Administrative Power to Impose Penalties for Environmental Issues]

\author{
Jorge Bermúdez Soto* \\ Pontificia Universidad Católica de Valparaíso, Chile
}

\begin{abstract}
Resumen
El ejercicio de la potestad sancionadora de la Administración del Estado en el ámbito ambiental es manifestación de la importancia que la protección del medio ambiente ha adquirido en la sociedad y de la asunción de la misma como función pública. El ejercicio de este poder se encuentra limitado tanto por los principios generales aplicables, pero además se somete a límites específicos al ámbito ambiental. Dichos límites pueden ser categorizados en tres clases: orgánicos, procedimentales y sustantivos. Todos
\end{abstract}

\begin{abstract}
The exercise of the power to impose penalties of the State Administration in relation to environmental matters is an evidence of the importance that the protection of the environment has gained in society and its acceptance as a public function. The exercise of this power is both limited by the general applicable principles and subject to limits specific to the environmental scope. Said limits can be categorized into three classes: organic, procedural and substantive. All of them are a control to and a balance for the
\end{abstract}

Recibido el 13 de marzo y aCEPTADo el 20 de mayo de 2013

* Profesor titular de Derecho Administrativo y Ambiental de la Escuela de Derecho de la Pontificia Universidad Católica de Valparaíso. Dirección postal: Avenida Brasil 2950, Valparaíso, Chile. Correo electrónico: jorge.bermudez@ucv.cl Este artículo ha sido elaborado en el marco del proyecto Fondecyt Regular No 1110791: "Fundamentos y Principios de la potestad sancionadora de la Administración del Estado en el Derecho chileno". 
ellos constituyen tanto un freno y un equilibrio al poder sancionador, y también una garantía para los particulares.

Palabras clave

Protección ambiental - Potestad sancionadora de la Administración Superintendencia del Medio Ambiente - Límites a la potestad sancionadora de la Administración. power to sanction as well as a guarantee for individuals.

KEYWORDS

Environmental protection - the Administration's power to impose penalties - Environmental Superintendent - Limits to the Administration's power to impose penalties.

\section{INTRODUCCIÓN ${ }^{1}$}

\section{1. ¿Por qué el Derecho debe asumir la protección ambiental?}

¿Es necesario proteger el medio ambiente? ¿Deben adoptarse medidas tendientes a la conservación de las especies y de la diversidad biológica? ¿Constituye un deber del Estado disminuir las emisiones de $\mathrm{CO}_{2}$ ? Estas son algunas de las cuestiones que es posible plantearse al momento de estudiar el Derecho de la protección ambiental. Estas preguntas pueden ser jurídicas, pero también son éticas.

El Derecho y la moral constituyen dos sistemas normativos diversos, pero evidentemente se encuentran relacionados, toda vez que el Derecho, en última instancia, debe justificarse a través de la Ética ${ }^{2}$. La protección ambiental asume el carácter de finalidad del Derecho y de ámbito de actuación de la Administración del Estado producto de la adopción de una conciencia ética, basada en la convicción de que mientras se protege el medio ambiente, también se está protegiendo a las personas que se vinculan a ese entorno, como también a las generaciones futuras. Tal predicamento es el reconocido como finalidad antropocéntrica del Derecho ambiental. Esto es, el ser humano como sujeto central de la protección ambiental; se protege el medio ambiente, porque con ello se garantiza la supervivencia de la especie humana. Sin embargo, cada vez es más común encontrar posiciones éticas, políticas y jurídicas que avalan que es el medio ambiente el que tiene un valor

${ }^{1}$ Abreviaturas más utilizadas: LBGMA. = Ley de bases generales del medio ambiente : LOSMA. = Ley orgánica de la Superintendencia del Medio Ambiente; LBGAE. = Ley Orgánica constitucional de bases generales de la Administración del Estado; SMA = Superintendencia del Medio Ambiente; rca = resolución de calificación ambiental; SEIA = Sistema de Evaluación de Impacto Ambiental.

${ }^{2}$ GORKE, Martin, Kann die biologische Vielfalt gerettet werden und wie wäre das zu bewerkstelligen? (Baden-Baden, Nomos, 2002), pp. 71 ss. 
en sí mismo, digno de ser considerado no tan sólo como objeto, sino también como un individuo o sujeto. Así las especies constituirían, a lo menos, un individuo histórico, según el planteamiento de algunos teóricos de la ciencia.

\section{El lugar del Derecho.}

Con el Derecho son asociados los conceptos de deber y sanción. El Derecho ambiental es, por una parte, Derecho, y por otra, una ciencia ambiental, como otras ciencias básicas que estudian el entorno. Sin embargo la ciencia jurídica consiste en el estudio del Derecho vigente, y no del Derecho que debería ser o el más eficiente. La ciencia jurídica no realiza una valoración de la cualidad de la norma o de la forma en que ésta debe ser perfeccionada, aunque indirectamente e incluso en ocasiones más o menos directamente, el estudio dogmático del Derecho sirva para dicho fin. Ello a diferencia de lo que ocurre con la política ambiental y el "management" ambiental. Ambos tienen por objetivo el perfeccionamiento de sus ámbitos. Por el contrario, en el estudio del Derecho se toma la norma como objeto de observación y análisis, con la finaldiad de determinar su mejor aplicación y su evolución. Y eso es lo que pretende hacer en este trabajo, específicamente, respecto de la configuración de la potestad sancionadora administrativa ambiental.

\section{El lugar de los ciudadanos y de la empresa en la protección del medio ambiente.}

Desde la perspectiva de la influencia de la empresa en la protección ambiental, por lo menos a primera vista, aquélla aparece como la causadora y en ocasiones dañadora del medio ambiente. Bajo este prisma debe definirse a la empresa como aquella organización que en una economía de mercado, bajo su propia decisión y riesgo produce bienes y servicios para ofrecerlos en el mercado. Como aspectos positivos de la actividad empresarial, podemos señalar que ellas crean empleo y riqueza, pagan impuestos y realizan o impulsan adelantos tecnológicos. El lado negativo de la actividad empresarial se encuentra en que ella provoca un daño - a veces colateral, a veces directo- al medio ambiente, al utilizar los bienes ambientales que son escasos y al emitir residuos en los medios o elementos ambientales. Por el contrario, cuando se piensa en la ciudadanía, pareciera que se trata de un grupo de sujetos pasivos, simples destinatarios de la acción del Estado o de las empresas, sin incidencia en la condición del medio ambiente. Sin embargo, muchas veces se olvida que como ciudadanos somos los destinatarios de esos bienes y servicios que las empresas entregan y producen, y por tanto, somos también responsables de los resultados ambientales que ellas provocan. 


\section{PRESUPUESTOS PARA UNA POLÍTICA DE PROTECCIÓN AMBIENTAL}

\section{Nivel de desarrollo económico.}

$\mathrm{Al}$ igual que en otras políticas de relevancia para la sociedad, el nivel de bienestar económico de una nación, medido como producto interno bruto, juega un rol decisivo en la protección ambiental. Es por ello que, por ejemplo, la "Declaración de Río" de 1992 fija en una posición central la lucha contra la pobreza como uno de los objetivos para favorecer la protección ambiental. La finalidad de protección ambiental y la intensidad de las medidas específicas en que se concreta, corresponden a una forma o manera de actuar que se identifica como una ética o conciencia ambiental de una determinada sociedad, pero también con una situación económica y unas finanzas públicas ordenadas, que permitan financiar la protección ambiental ${ }^{3}$.

\section{Grado de conciencia social respecto de la protección ambiental.}

Normalmente, se acepta como un tópico que en la medida en que la sociedad civil se desarrolla, ésta adquiere una mayor conciencia acerca de la problemática ambiental y de la protección del entorno. Esto es así, en cuanto en la protección del medio ambiente se juega buena parte de la calidad de vida de la sociedad. Sin embargo, y a pesar de que el ser humano depende de las bases naturales o medio ambiente natural para sobrevivir, es posible afirmar que en la actualidad las sociedades -que principalmente viven en ciudades- se encuentran en situaciones de desaprensión e ignorancia ambiental ${ }^{4}$. Ello se explica por el desapego que existe a los ciclos naturales y la incomprensión que la mayor parte de la sociedad tiene de éstos. En este punto entra en juego un instrumento de la institucionalidad que es clave: el acceso a la información ambiental.

\section{Institucionalidad ambiental.}

Es esencial para la protección ambiental contar con una Administración Pública especializada en la coordinación de la política ambiental. Asimismo, que las administraciones sectoriales cuenten con departamentos especiali-

\footnotetext{
${ }^{3}$ Bermúdez, Jorge, Fundamentos de Derecho Ambiental (Valparaíso, Ediciones Universitarias de Valparaíso, 2007), p. 28. Cfr. BREUER, Rüdiger, Umweltschutzrecht, en Schmidt-AßMann, Eberhard (editor), Besonderes Verwaltungsrecht (11 a edición, Berlín 1999), p. 467. Sobre el tema de la financiación de la protección ambiental, véase: Kilian, Michael, Finanzierung des Umweltschutzes, en Rengeling, HansWerner (editor), Handbuch zum europäischen und deutschen Umweltrecht (Köln, Carl Heymanns, 1998), pp. 71 ss.

${ }^{4} \mathrm{Cfr}$. BermúdeZ, Jorge, El acceso a la información pública y la justicia ambiental, en Revista de Derecho de la Pontificia Universidad Católica de Valparaiso, 34 (Valparaíso, primer semestre de 2010), pp. 573-574.
} 
zados para la formulación de políticas, normas, autorización y fiscalización ambientales constituyen un requisito sine qua non para alcanzar la protección ambiental.

La incorporación del ambiente como objeto de protección por parte de los órganos estatales modifica la organización de la Administración Pública, así como su funcionamiento. Aunque los Estados pueden configurar libremente su modelo de organización administrativa, la eficacia ambiental es siempre requerida ${ }^{5}$. De aquí la importancia de una organización adecuada del complejo administrativo para la protección del medio ambiente. Siguiendo el modelo nacional, ésta podrá ser "funcional y territorialmente descentralizada, o desconcentrada en su caso, de conformidad a la ley" (artículo 3 C.Pol.). Ambas técnicas han sido incorporadas en la LBGMA. y suponen diferencias relevantes, tanto para la planificación y gestión del instrumento de protección, como en relación al patrimonio y el control de la actuación administrativa. Conforme a la modificación introducida por la Ley $\mathrm{N}^{\circ}$ 20.417, la Administración Ambiental ha sido configurada mediante múltiples órganos: el Ministerio del Medio Ambiente; el Consejo de Ministros para la Sustentabilidad; el Servicio de Evaluación Ambiental; y la Superintendencia del Medio Ambiente. Todos estos órganos poseen una naturaleza jurídica diversa y en términos generales, la Ley $\mathrm{N}^{\circ} 20.417$ ha distribuido en ellos las competencias antiguamente atribuidas a la Comisión Nacional del Medio Ambiente.

Sin embargo, la Administración Pública ambiental no se identifica únicamente con órganos que pasan a formar parte de la Administración del Estado. Si fuera sólo eso, estaríamos hablando simplemente de sustitución de administraciones y no de una nueva institucionalidad ambiental. Por el contrario, institucionalidad comprende: órgano, potestades, procedimiento administrativo y normas sustantivas.

\section{LA POTESTAD SANCIONADORA}

COMO INSTRUMENTO PARA LA PROTECCIÓN AMBIENTAL

\section{Actividad de policía de la Administración en resguardo del orden pú- blico.}

Tradicionalmente se entiende que la Administración Pública desarrolla diversas actividades para el cumplimiento de sus fines de satisfacción del in-

${ }^{5}$ Conforme al Principio 11 de la "Declaración de Río": "Los Estados deberán promulgar leyes eficaces sobre el medio ambiente. Las normas, los objetivos de ordenación y las prioridades ambientales deberian reflejar el contexto ambiental y de desarrollo al que se aplican. Las normas aplicadas por algunos paises pueden resultar inadecuadas y representar un costo social y económico injustificado para otros países, en particular los paises en desarrollo". 
terés público, destacándose las actividades prestacional o de servicio público; de fomento; y de policía. Esta última suele ser definida como aquella actividad que la Administración despliega en el ejercicio de sus propias potestades y por la cual, para garantizar el mantenimiento del orden público, limita los derechos de los administrados mediante el ejercicio de la coacción sobre los mismos $^{6}$. En otros términos, en ejercicio de la actividad de policía la Administración opera controlando las actividades de los particulares para que su libre desarrollo se acomode al bien público; para ello ejerce limitaciones, impone conductas y ajusta aquéllas a las exigencias del interés general 7 .

Así, la actividad de policía busca garantizar a la comunidad que sus individuos ejercerán sus derechos de propiedad y libertad sin dañar o afectar los derechos o intereses del resto de la colectividad. Para tal efecto, la Administración, a través del ordenamiento jurídico, cuenta con tres clases de poderes: i) la reserva de autorización -considerada ésta en un sentido amplio- que consiste en la posibilidad de realizar ciertas actividades sólo si se cuenta con la previa autorización expresa de la Administración del Estado; ii) la regulación, que se manifiesta en el ejercicio de las potestades reglamentarias, a través de la cual se imponen exigencias de conductas, limitaciones y restricción de actividades con la finalidad de alcanzar la satisfacción de necesidades públicas y mantención del orden público; y iii) la potestad sancionadora, que permite a la Administración imponer directamente sanciones administrativas. Desde el momento en que la protección del medio ambiente pasa a ser un ámbito de interés y relevancia para la colectividad es que los instrumentos de policía pasan a tener un rol trascendental en su consecución.

\section{Potestad sancionatoria de la Administración.}

La obligatoriedad de las normas jurídicas que establecen dichas limitaciones para garantizar el respeto al orden público exige, lógicamente, que el ordenamiento establezca mecanismos de reacción frente a las conductas que las incumplan ${ }^{8}$. Cuando las conductas infractoras causan una lesión en intereses colectivos, o bien revisten especial gravedad, la reacción posee carácter represivo, consistiendo en la imposición de un mal o castigo al infractor?.

Así, en caso de perturbación, la actividad de policía pasa a denominarse de policía represiva, que tiene por función investigar y sancionar la infracción

${ }^{6}$ Garrido Falla, Fernando, Los medios de policía y la teoría de las sanciones administrativas, en Revista de Administración Pública, 28 (1959), p. 12.

${ }^{7}$ Mondaca, Alberto, Significado y técnica jurídica de la policía administrativa, en Revista de Administración Pública, 28 (1959), p. 54.

${ }^{8}$ Santamaría Pastor, Alfonso, Principios de Derecho administrativo (Madrid, Centro de Estudios Ramón Areces, 2002), II, p. 371.

${ }^{9}$ Ibíd. 
que se ha cometido en contra del orden público, para lograr su restablecimiento. Para el ejercicio de tal actividad, es decir, la represión de las infracciones contra el orden público, la Administración se encuentra provista de un conjunto de potestades. Una de dichas potestades corresponde a la potestad sancionadora que permite a la Administración reprimir, directamente y sin necesidad de acudir a los tribunales, mediante la imposición de sanciones administrativas, las infracciones al ordenamiento jurídico.

En suma, en ejercicio de dicha potestad la Administración puede imponer sanciones a los particulares por las transgresiones del ordenamiento jurídico previamente tipificadas como infracciones administrativas por una norma ${ }^{10}$.

Dentro del catálogo de sanciones que la Administración se encuentra facultada para imponer ante el supuesto que permite el ejercicio de la potestad sancionadora se encuentran la multa, por la cual se condena al infractor a pagar una determinada suma de dinero que va a incorporarse a las arcas públicas; la suspensión de un derecho; la privación de un derecho; y la revocación sancionadora de los títulos administrativos que habilitan para realizar la actividad en cuyo seno se ha cometido la infracción. Esta última, la revocación sanción, deja sin efecto el título administrativo que puede consistir en una autorización o permiso y que remueve el obstáculo para ejercer un derecho preexistente, en la especie, la libertad de desarrollar actividades económicas, respetando las normas legales que la regulan.

\section{Aplicación matizada de los principios penales en el ámbito de la potestad} sancionadora de la Administración.

La explicación actualmente más aceptada a nivel doctrinal respecto de la naturaleza de la potestad sancionadora es que ésta, junto con la potestad penal, integran el denominado iuspuniendi del Estado. Ya que, ambas clases de potestades represivas comparten elementos esenciales, se ha postulado la aplicación de los principios y garantías penales al ámbito de la potestad sancionadora de la Administración.

Sin embargo, tal extrapolación no es absoluta, ya que, los principios penales son matizados y morigerados en sus alcances y efectos, haciendo que ellos, en el ámbito administrativo, adquieran autonomía y contenido propio.

${ }^{10}$ Cano, Tomás, Derecho administrativo sancionador, en Revista Española de Derecho Constitucional, 43 (enero-abril de 1995), p. 339. En tal sentido, como señala SuAY, José, El Derecho administrativo sancionador: Perspectivas de reforma, en Revista de Administración Pública, 109 (enero-abril de 1986), p. 208, que la Administración aplica el Derecho positivo al objeto de restablecer la paz jurídica quebrantada previamente por el infractor, es decir, actúa para salvaguardar la puntual efectividad del ordenamiento jurídico. 
Así lo destacan diversos autores a nivel comparado, como se aprecia en la opinión del profesor Gonzalo Quintero, quien expresa: "La infracción y sanción administrativa está destinada a someterse a muchos de los principios procedimentales y materiales que gobiernan y limitan la apreciación de delitos y la imposición de penas, pero no a todos. La responsabilidad criminal y su medición o negación ofrecen criterios utilizables en buena medida por el sistema sancionador, pero no plenamente" 11 .

En el mismo sentido se pronuncia el Tribunal Supremo español en sentencia de 8 de abril de 1981, que concluye: "Los principios del orden penal son de aplicación, con ciertos matices, al Derecho administrativo sancionador, dado que ambos son manifestaciones del ordenamiento punitivo del Estado"12, destacando con ello, según el profesor Tomás Cano, "las profundas diferencias estructurales, organizativas y funcionales que existen entre la potestad sancionadora de la Administración y la potestad penal de los Tribunales, y demostrando la incorrección de una identificación absoluta entre los principios del Derecho Penaly del Derecho Administrativo sancionador"13.

La misma prevención efectúa el Tribunal Constitucional español, como apunta Lozano: "Así lo reconoce el TC en la Sentencia que nos ocupa, en la que comienza por recordar, una vez más, que los principios inspiradores del orden penal son de aplicación, con ciertos matices, al Derecho administrativo sancionador, pero advierte -como ya había hecho en otras ocasiones- que debe operarse con cautela cuando se trata de trasladar garantías constitucionales extraídas del orden penal al Derecho administrativo sancionador. Esta operación, se dice en la Sentencia, 'no puede hacerse de forma automática, porque la aplicación de dichas garantías al procedimiento administrativo sólo es posible en la medida en que resulten compatibles con su naturaleza' (STC 22/1990)"14.

Entre nosotros, el Tribunal Constitucional chileno se ha pronunciado en idéntico sentido en variadas ocasiones. Así, por ejemplo, en la sentencia rol $\mathrm{N}^{\circ}$ 244 de 2006, establece en su considerando 9०: "Que los principios inspiradores del orden penal contemplados en la Constitución Politica de la República han de aplicarse, por regla general, al derecho administrativo sancionador, puesto que ambos son manifestaciones del ius puniendi propio del Estado". Posterior-

${ }^{11}$ Quintero, Gonzalo, La autotutela, los limites al poder sancionador de la Administración Pública y los principios inspiradores del Derecho penal, en Revista de Administración Pública, 126 (septiembre-diciembre de 1991), p. 293.

${ }^{12}$ SuAy, José, El Derecho administrativo sancionador, cit. (n. 10), p. 212.

${ }^{13}$ Cano, Tomás, Derecho administrativo sancionador, cit. (n. 10), p. 344.

${ }^{14}$ Lozano, Blanca, La responsabilidad de la persona jurídica en el ámbito sancionador administrativo. (A propósito de la STC 246/1991, de 19 de diciembre), en Revista de Administración Pública, 129 (septiembre-diciembre de 1992), p. 223. 
mente, la sentencia rol No 479, en su considerando $8^{\circ}$ concluye: "Como ba tenido oportunidad de establecer esta Magistratura, aún cuando las sanciones administrativas y las penas difieran en algunos aspectos, ambas forman parte de una misma actividad sancionadora del Estado y han de estar, en consecuencia, con matices, sujetas al mismo estatuto constitucional que las limita en defensa de la igual protección de la ley en el ejercicio de los derechos".

En definitiva, en una perspectiva que tiende a la autonomía de la potestad sancionadora de la Administración Pública "Las normas de derecho penal y derecho procesal penal no son nunca aplicables a las sanciones administrativas. Ni siquiera se trata de que sean aplicables cuando no hay una norma específica de derecho administrativo. Simplemente, se trata sólo de aceptar algunos principios comunes que, incluso así, tendrán una plasmación diferente en el derecho penal y en el derecho administrativo sancionador"15. Lo que resulta indudable es la relación entre los ámbitos punitivos penal y administrativo, ya que, "ni el derecho penal ni el derecho administrativo sancionador son estancos separados, sino que son espacios de actuación coordinada en el marco de una política represiva que el Estado puede implementar para cumplir su función constitucional. Existe un espacio que es propio o inherente al derecho penal, en donde la administración no tiene cabida (Derecho penal nuclear o "Kernstraftsrecht"), pero también existe otro ámbito en donde la eficacia en el actuar del Estado no se asegura solo con la intervención de la administración, sino que requiere también la participación del poder judicial mediante sanciones de la mayor gravedad (Derecho penal colateral o "Nebenstraftsrecht"). Es en este espacio donde juega la sanción administrativa y comienza su relación dialéctica con las sanciones penales" ${ }^{16}$.

\section{La potestad sancionadora como instrumento de protección ambiental.}

La protección del medio ambiente impone verdaderas obligaciones de resultado. De aquí la importancia de la organización y funcionamiento de la Administración fiscalizadora y sancionadora para el Derecho ambiental. Sólo asegurando las capacidades de represión pueden garantizarse los bienes jurídicos protegidos de manera preventiva.

Hasta la dictación Ley $\mathrm{N}^{\circ} 20.417$, las actividades fiscalizadoras eran desarrolladas exclusivamente por servicios públicos sectoriales. Las atribuciones

${ }^{15}$ Rebollo, Manuel, y otros, Panorama del Derecho administrativo sancionador en España, en Revista Estudios Socio-Jurídicos, 7 (Bogotá, enero-junio de 2005) 1, pp. 27-28.

${ }^{16}$ Cordero, Eduardo, El Derecho administrativo sancionador y su relación con el Derecho penal, en Revista de Derecho, Universidad Austral de Valdivia, 25 (diciembre de 2012) 2, p. 155. 
de la extinta Comisión Nacional del Medio Ambiente (CONAMA) se relacionaban con su comunicación y coordinación, lo que le valió múltiples críticas y sarcasmos ${ }^{17}$. En efecto, el modelo de coordinación de CONAMA planteaba dificultades prácticas y jurídicas para su aplicación. Lo anterior se debía a que la Administración ambiental carecía de competencias para forzar la fiscalización por parte de las Administraciones sectoriales coordinadas, cuyo personal y medios mantenían títulos de intervención diversos a la protección ambiental ${ }^{18}$. Las fiscalizaciones eran también fragmentadas en múltiples instituciones, cada una de las cuales podía aplicar distintos criterios. Finalmente, los déficits presupuestarios contribuyeron también a un resultado insuficiente.

Algunas estrategias para superar tales problemas fueron realizadas respecto de ciertos instrumentos, como el SEIA, a través de los denominados Comités Operativos de Fiscalización $(\mathrm{COF})^{19}$. Sin embargo, estos mecanismos carecían de una regulación orgánica y procedimental. Asimismo, su vocación era acotada, viéndose limitados sólo al SEIA. A todo ello, deben agregarse las críticas sobre la eficacia de los mecanismos de represión, así como al acceso a la justicia administrativa y judicial ${ }^{20}$.

Lo anterior fue plasmado en el Informe de Desempeño Ambiental de Chile elaborado por la OCDE (2005) que, antes de proponer la creación de un Ministerio, estimó necesario centrar la reforma en la fiscalización de los instrumentos ya existentes. Así se señaló, al requerir: "examinar formas de fortalecer la capacidad de cumplimiento y fiscalización, incluso mediante reformas institucionales, como por ejemplo el establecimiento de un órgano de inspección ambiental".

Existieron distintas alternativas para superar estos problemas. Desde el aumento de recursos para órganos sectoriales, hasta la mantención de las competencias fiscalizadoras, incorporando una Superintendencia para em-

\footnotetext{
${ }^{17}$ Astorga, Eduardo, Derecho ambiental chileno. Parte general (Santiago, LexisNexis, 2006 [hay una edición posterior]), pp. 306-308.

${ }^{18}$ Según fuentes de CONAMA, se estimaba que los funcionarios sólo destinaban un $20 \%$ de su trabajo a fiscalización, y un $17.7 \%$ del tiempo a labores relacionadas con el SEIA. En este sentido, Cordero Vega, Luis, Evaluando el Sistema de Fiscalización Ambiental chileno. Desarrollo sustentable: gobernanza y Derecho, en Actas de las Cuartas Jornadas de Derecho Ambiental (Santiago, 2008), p. 37.

${ }^{19}$ Creados conforme al artículo 77 LBGMA., mediante Acuerdo $N^{\circ} 112 / 99$ del Consejo Directivo.

${ }^{20}$ Estos dos aspectos comprenden las críticas a las multas de bagatela incorporadas en la LBGMA., cuyos montos se limitaban a las 500 UTM. Asimismo, el acceso a la justicia suponía el ejercicio de principio "solve et repete", mediante la consignación de un porcentaje de las sumas, situación que afectaba a la defensa de los administrados.
} 
presas $^{21}$. Finalmente, el legislador de la Ley № 20.417 optó por la creación un servicio público ambiental: la Superintendencia del Medio Ambiente, asignándole competencias exclusivas en materia de fiscalización, como también potestades excluyentes respecto de la imposición de sanciones y, asimismo, otras atribuciones en mayor o menor medida relacionadas con ambos mecanismos de intervención administrativa.

\section{LÍMITES AL EJERCiCiO DE LA POTESTAD SANCIONADORA-AMBIENTAL}

El ejercicio de la potestad sancionadora en el ámbito de la protección del medio ambiente reconoce ciertos límites jurídicos, los que no se deducen tan claramente a propósito del ejercicio de este poder sancionador en otros sectores de la actividad de policía, por parte de otros órganos de la Administración del Estado. Dichos límites es posible agruparlos en tres categorías: orgánicos, procedimentales y sustantivos.

\section{Limites orgánicos: la Superintendencia del Medio Ambiente.}

Para el Derecho administrativo, las superintendencias corresponden a órganos descentralizados, desde la perspectiva funcional; y es también el caso de la Superintendencia del Medio Ambiente. Conforme al artículo 1 LOSMA., la Superintendencia corresponde a un "servicio público funcionalmente descentralizado, dotado depersonalidad juridica y patrimonio propio, sometido a la supervigilancia del Presidente de la República a través del Ministerio del Medio Ambiente".

$\mathrm{Al}$ igual como ocurre respecto del Servicio de Evaluación Ambiental -que es el otro servicio que se ordena en el sector ambiental-, las competencias de la Superintendencia no se relacionan con una universalidad de objetivos de protección ambiental, sino con una parcela limitada. En este caso, la delimitación funcional presenta algunas características relevantes:

i) En primer lugar, las Superintendencias forman parte de los organismos para el control de las actividades económicas ${ }^{22}$. Este carácter es compartido por la Superintendencia del Medio Ambiente. En este sentido, aunque

${ }^{21}$ GuIloff, Matías, Reforma a la institucionalidad ambiental: un análisis desde el diseño institucional, en Reforma a la institucionalidad ambiental: antecedentes y fundamentos, programa de derecho y politica ambiental (Santiago, Ediciones de la Universidad Diego Portales, 2010), p. 46.

${ }^{22}$ Para una visión crítica respecto de las potestades que asumen las Superintendencias en general: GARCíA, José Francisco, ¿Inflación de superintendencias? Un diagnóstico crítico desde el derecho regulatorio, en Revista Actualidad Jurídica, 10 (enero de 2009) I, p. 327 ss. 
muchos de los instrumentos bajo sus competencias poseen una naturaleza normativa y reguladora ${ }^{23}$, y por ende preventiva o precautoria, ellas también integran instrumentos de carácter represivo. Lo anterior implica ejercer poderes de fiscalización y, eventualmente, la aplicación de sanciones administrativas, incluso respecto de instrumentos emanados de otros órganos de la Administración, como las Resoluciones de Calificación Ambiental.

ii) Por otra parte, sus poderes jurídicos no recaen sobre un instrumento específico. A diferencia del Servicio de Evaluación Ambiental, las potestades de la Superintendencia se extienden a los instrumentos de gestión ambiental en general. Así se desprende de artículo 2 LOSMA., al señalar que quedan bajo sus competencias “todos aquellos otros instrumentos de carácter ambiental que establezca la ley". En virtud de ello, la competencia sólo se unifica en tanto organismo de fiscalización y sanción, presentando variaciones en relación a las tipologías de instrumentos que deberán ser fiscalizados y eventualmente sancionados. Por tanto, la consideración del instrumento que se fiscaliza es un factor que incidirá de manera directa en la forma y extensión en que deberá desarrollar sus funciones. Esta variedad de instrumentos a fiscalizar y su número, justifican tanto las técnicas de programación previstas por el legislador (los denominados programas de fiscalización), como la determinación de ser ejercidas las competencias fiscalizadoras directas por la propia Superintendencia; a través de órganos fiscalizadores sectoriales; o bien, a través de la intervención de empresas consultoras especializadas.

a) Potestad fiscalizadora exclusiva. Con anterioridad a la Ley $\mathrm{N}^{\circ}$ 20.417 las competencias fiscalizadoras eran atribuidas a órganos sectoriales. La extinta CONAMA sólo poseía potestades de coordinación y la sanción administrativa correspondía a la COREMA. Estas competencias quedaban acotadas estrictamente a los proyectos sometidos al SEIA. En este caso, el antiguo artículo 64 LBGMA. disponía que las autoridades participantes podían solicitar la imposición de sanciones a la Comisión Regional o Nacional del Medio Ambiente. En los restantes supuestos, esto es, frente a otros instrumentos de gestión ambiental, CONAMA carecía de competencias. Por ello, la fiscalización no operaba de manera unificada. Las potestades fueron atribuidas por la ley a organismos sectoriales, que mantuvieron sus atribuciones respecto de instrumentos no incorporados en resoluciones de calificación ambiental. Respecto de aquéllos sí incorporados en tales resoluciones, ellos ampliaban sus facultades fiscalizadoras, pudiendo denunciar cualquier incumplimiento y no sólo aquéllos relacionados con sus competencias. No

${ }^{23}$ Camacho Cepeda, Gladys, La problemática de la potestad normativa de las superintendencias, en Actas de las XXXIV Jornadas de Derecho Público (Santiago, LexisNexis, 2005), p. 423-425. 
obstante, sus potestades sancionadoras fueron limitadas en tales casos, al radicarse exclusivamente en CONAMA, a través de Comisiones Regionales o su Dirección Ejecutiva, en aplicación de la jurisprudencia administrativa sobre estos aspectos ${ }^{24}$.

Este escenario cambia con la ley que crea la Superintendencia del Medio Ambiente ${ }^{25}$. En efecto, la competencia característica de la Superintendencia corresponde a sus facultades sancionadoras, por ser aquélla la que, como se verá, debe ejercer de manera excluyente.

De forma previa al ejercicio del poder sancionador, la Superintendencia debe ejercer las atribuciones de fiscalización de los instrumentos que la ley le encomienda. A diferencia de la regulación anterior, actualmente la SMA posee facultades de fiscalización exclusiva sobre los instrumentos a que se refiere el artículo 2 inciso $1^{\circ}$ LOSMA. En efecto, la ejecución de estas labores ha sido consagrada de manera exclusiva respecto de la Superintendencia al disponer que ella tiene por objeto "ejecutar, organizar y coordinar el seguimiento y fiscalización" de los instrumentos de protección señalados por dicha disposición, así como de todos aquellos otros instrumentos de carácter ambiental que establezca la ley. Acto seguido, la norma confirma dicha exclusividad al dispone en el artículo 2 inciso $2^{\circ}$ LOSMA. Que: "Los organismos sectoriales que cumplan funciones de fiscalización ambiental, conservarán sus competencias y potestades de fiscalización, en todas aquellas materias e instrumentos que no sean de competencia de la Superintendencia". En virtud de dicha disposición todo órgano sectorial con competencias de fiscalización sobre los instrumentos ambientales que hoy día corresponden a la SMA estará impedido de ejercer dicha competencia de forma directa. Desde la perspectiva del Derecho administrativo, lo que hace la LOSMA es entregar a la Superintendencia la fiscalización ambiental como una competencia esencial, es decir, aquélla que le da razón de ser y justifica su existencia. Los demás órganos sectoriales con competencia en la fiscalización de los instrumentos de gestión ambiental, si bien conservan dicho poder respecto de todas aquellas materias que no correspondan a la SMA, no pueden ejercerlo de manera directa, a menos, como se verá, que hubieren sido incluidos en un subprograma de fiscalización.

b) Labores de fiscalización. La fiscalización se traduce la ejecución de labores de inspección, control, medición y análisis. Si bien no se define expresamente por la LOSMA., estas actividades son las que se señalan en el artículo 3 letra a) a propósito de la fiscalización de la RCA. Luego el artículo 22, ubicado dentro del título $2^{\circ}$ : De la fiscalización ambiental, no menciona

\footnotetext{
${ }^{24}$ Dictamen No 981 de 2003 de la Contraloría General de la República.

${ }^{25}$ La LOSMA. se encuentra contenida en el artículo 2 de la Ley No 20.417.
} 
las labores de control como parte de la fiscalización. Por su parte, la SMA definió la fiscalización ambiental como "conjunto de actividades llevadas a cabo por un fiscalizador, el que puede constar de las siguientes etapas: Inspección Ambiental; Examen de la Información; Mediciones y Análisis; $y /$ Informe de Fiscalización Ambiental; y que está destinada a verificar el cumplimento de las normas, condiciones y medidas establecidas en las resoluciones de calificación ambiental ${ }^{26}$. Esta inconsistencia normativa a la hora de definir las labores que forman parte de la fiscalización podría traer problemas en la práctica, si al pretender llevarse a cabo una actividad supuestamente fiscalizadora, ésta comprende labores que no han sido señaladas como tales por la ley.

Independientemente de las labores que comprenda la fiscalización, lo esencial de la misma radica en la inspección apuntada a un fin de verificación del cumplimiento de normativa o condiciones de operación. Este extremo resulta muy importante, toda vez que la fiscalización no sólo recae sobre la verificación del cumplimiento normativo (por ejemplo, si está o no dentro de los parámetros de emisión fijados por una norma), sino que en la práctica será mucho más relevante la comprobación del cumplimiento de las condiciones de operación que se incorporan en las autorizaciones de funcionamiento ambiental. En efecto, la RCA no sólo implica una incorporación de parámetros normativos, sino que una serie de condiciones específicas del proyecto autorizado. "Se trata de un ámbito de mayor intensidad de intervención administrativa sobre la actividad de los sujetos privados, constituido por técnicas que no se limitan a condicionar el ejercicio de la actividad que se pretende a un examen por parte de la Administración del cumplimiento de determinados requisitos legales, sino que inciden directamente en su esfera jurídica, tanto en sus aspectos de libertad como patrimoniales, que crean contenidos de situaciones jurídicas desfavorables o de carácter pasivo, como lo son las obligaciones prohibiciones que habitualmente se establecen en toda $\mathrm{RCA}^{\prime 27}$. En ese sentido, la RCA contiene un conjunto de cláusulas accesorias, que determinan que las consecuencias jurídicas previstas por la norma sean concretizadas por la decisión administrativa, o bien, que el contenido del acto administrativo corresponda, en parte, a la expresión formal de una consecuencia jurídica no dispuesta expresamente por la norma, sino que decidida por la Administración ${ }^{28}$.

${ }^{26}$ Resolución SMA No 879 de 2012, que establece los "Programas y Subprogramas Sectoriales de fiscalización ambiental de las Resoluciones de Calificación Ambiental para el año 2013".

${ }^{27}$ SePúlvedA, Doris, Invalidación sobreviniente: El caso de la Resolución de Calificación Ambiental (Santiago, Abeledo Perrot - Thomson Reuters, 2012), p. 27.

${ }^{28}$ Velasco, Francisco, Las cláusulas accesorias del acto administrativo (Madrid, Tecnos, 1996), p. 66. 
c) Fiscalización directa. Existe una distinción clara en la LOSMA. entre el titular de la potestad fiscalizadora directa, y la forma en que ella se lleva a cabo. Para ello la primera decisión del legislador en la Ley No 20.417 fue evitar la duplicidad de competencias en el ejercicio de las potestades de fiscalización ${ }^{29}$. A lo largo de la LOSMA. es posible encontrar disposiciones que dan cuenta de una potestad de fiscalización directa por parte de la Superintendencia y otras que la sitúan en una posición de dirección de la fiscalización ambiental. Entre las primeras se encuentran los artículos 2 inciso $1^{\circ}$ y 3 letras a), b), d) y n) LOSMA. Entre las segundas, de dirección de la fiscalización, se debe tener en cuenta el artículo 2 inciso $3^{\circ}$ LOSMA., el cual dispone que: "Los organismos sectoriales que cumplan funciones de fiscalización ambiental, deberán adoptar y respetar todos los criterios que la Superintendencia establezca en relación a la forma de ejecutar las actuaciones de fiscalización, pudiendo solicitar a ésta que se pronuncie al respecto". Dichos criterios obligatorios se plasman en actos normativos de la Superintendencia en virtud de lo dispuesto en el artículo 3 literales ñ) y s) LOSMA. y con la facultad de impartir directrices a los organismos sectoriales de fiscalización, debiendo informarles a éstos respecto de la ejecución inspecciones, mediciones y análisis, con el objeto de evitar duplicidad de funciones (artículo 22 inciso $2^{\circ}$ LOSMA.); lo anterior se reitera en el artículo 25 LOSMA., señalando que "los organismos sectoriales competentes, deberán ajustarse a las instrucciones técnicas de carácter general impartidas por ésta [la Superintendencia] relativas a los protocolos, procedimientos y métodos de análisis en ellas definidos". A ello se agrega la facultad instrumental que entrega la ley a la SMA de requerir a los organismos sectoriales que cumplan labores de fiscalización ambiental, las informaciones y datos que sean necesarios para el debido cumplimiento de sus funciones (artículo 2 letra e).

d) Fiscalización programada y subprogramada. La fiscalización puede ser ejecutada directamente por la SMA a través de sus propios funcionarios fiscalizadores; por los organismos sectoriales con competencia ambiental o bien a través de los organismos privados que hubieren sido previamente acreditados. Para ordenar y llevar a cabo una fiscalización eficiente, la ley reconoce dos nuevos instrumentos denominados programa y subprograma de fiscalización. Los programas y subprogramas de fiscalización se crean por la ley como instrumentos de planificación de la fiscalización ambiental. Estos instrumentos corresponden a una forma clásica en que la Administración elabora un pronóstico de actuación, fijando las directrices de las tareas que se deben emprender. Evidentemente, la decisión de incluir

${ }^{29}$ Lo que, en realidad, constituye una aplicación de lo dispuesto en el artículo 5 inciso $2^{\circ}$ de la LBGAE. 
o no un sector productivo entre los objetivos de fiscalización, así como la intensidad de la fiscalización misma; o bien, el encomendamiento de mayores tareas a un servicio sectorial en un subprograma, corresponden todas a decisiones de carácter político, sin perjuicio de las posibilidades de control sobre la decisión que se plasma en el programa cuando ellas contravienen el ordenamiento jurídico, es irracional o arbitraria. Asimismo, dentro de la tipología de los instrumentos de planificación, los programas y subprogramas tienen un carácter imperativo ${ }^{30}$, es decir, corresponden a verdaderas órdenes o instrucciones obligatorias en que la SMA se obliga a ejecutar, o bien que encomienda a los servicios sectoriales.

Dado el carácter imperativo del programa y subprograma, los organismos sectoriales no podrán decidir independientemente si fiscalizarán o no un determinado instrumento, sino que se encontrarán vinculados por el plan de fiscalización que ha efectuado para un año determinado la SMA. Asimismo, sólo la SMA podrá flexibilizar el contenido del programa en casos de denuncias o reclamos o en que tome conocimiento de incumplimientos o infracciones, en cuyo caso podrá disponer inspecciones no previstas en aquél (artículo 19 inciso $1^{\circ}$ LOSMA.). Se trata de la aplicación del principio de participación en el ámbito de la fiscalización, ya que, conforme al artículo 21: "Cualquierpersona podrá denunciar ante la Superintendencia el incumplimiento de instrumentos de gestión ambiental y normas ambientales, debiendo ésta informar sobre los resultados de su denuncia en un plazo no superior a 60 dias hábiles./ En el evento que producto de tales denuncias se iniciare un procedimiento administrativo sancionador, el denunciante tendrá para todos los efectos legales la calidad de interesado en el precitado procedimiento".

De lo antes expuesto, entonces, se desprenden las siguientes categorías de fiscalización, en virtud del instrumento objeto de fiscalización y el órgano o entidad que la lleva a cabo, a saber:

i) Fiscalización programada, ejecutada directamente por la SMA. En este caso, el programa de fiscalización determinará las actividades de fiscalización ambiental que deberá ejecutar directamente la Superintendencia, el presupuesto asignado a dichas actividades, así como el indicador de desempeño asociado $^{31}$.

ii) Fiscalización subprogramada, ejecutada directamente por los órganos sectoriales. Corresponde a aquellas labores de fiscalización que deben ejecutar los órganos sectoriales con competencia ambiental. Al igual que en

\footnotetext{
${ }^{30}$ Schmidt-Assmann, Eberhard, Das allgemeine Verwaltungsrecht als Ordnungsidee (2a edición, Berlin - Heidelberg, Springer, 2006), p. 332.

${ }^{31}$ Artículo 2, Resolución SMA No 879, de 2012, que establece los "Programas y Subprogramas Sectoriales de fiscalización ambiental de las Resoluciones de Calificación Ambiental para el año 2013”.
} 
el programa, en el subprograma de fiscalización se indicarán el presupuesto asignado y los indicadores de desempeño asociados. Uno de los mecanismos que permiten la aplicación eficaz de los programas y subprogramas dice relación con la determinación de un porcentaje de cumplimiento del programa o subprograma con los indicadores de desempeño de los jefes de servicios sectoriales y de sus equipos de trabajo.

iii) Fiscalización programada o subprogramada ejecutada por entidades acreditadas. Excepcionalmente las acciones de fiscalización, sea que correspondan a la SMA o a órganos sectoriales, las podrán ejecutar entidades privadas, previamente acreditadas, en caso de que exista insuficiencia de operativa de los servicios sectoriales o por otra causa justificada (artículo 24 LOSMA). Evidentemente, se abre aquí la discusión doctrinal y política relativa a la intervención de sujetos privados en la ejecución de labores de policía $^{32}$.

\section{Limites procedimentales.}

Los límites procedimentales dicen relación con la forma en que se debe canalizar el ejercicio de la potestad sancionadora por parte de la SMA y comprenden: el procedimiento administrativo sancionador; la separación de funciones de fiscalización, investigación y sanción y las reglas de inhibición de ejercicio de la potestad sancionadora.

a) Procedimiento administrativo sancionador. A diferencia de lo que ocurre en la mayor parte de los órganos administrativos que ejercen potestades sancionadoras, la LOSMA dedicó un párrafo completo destinado al procedimiento administrativo sancionador (artículos 47 a 54). Desde el momento en que, por aplicación expresa del artículo 62 LOSMA., la LBPA. tiene aplicación supletoria en el procedimiento administrativo sancionador, se puede deducir que al igual que el procedimiento administrativo general, la orientación del procedimiento administrativo sancionador es la de adopción de una decisión con carácter vinculante para su destinatario. La sola existencia de una adecuada densidad normativa en la que se contengan las normas procedimentales mínimas es constitutiva de un límite al ejercicio de la potestad sancionadora y por ende, es una garantía ${ }^{33}$ en una doble perspectiva:

i) De correcta aplicación del ordenamiento jurídico. La que se identifica

${ }^{32}$ A propósito del ejercicio de potestades públicas por parte de entidades autónomas, cfr. Rojas, Christian, Los organismos autónomos y la Administración del Estado, en Estudios sobre la Ley Orgánica Constitucional de Bases Generales de la Administración del Estado. Actas de las Terceras Jornadas de Derecho Administrativo (Antofagasta), pp. 135-163.

${ }^{33}$ García Gómez de Mercado, Francisco, Sanciones administrativas, garantías, derechos y recursos del presunto responsable (Granada, Comares, 2004), p. 105. 
con la función tradicional del procedimiento administrativo, esto es, de asegurar que la decisión que se adopte, que el producto del procedimiento, sea manifestación o realización del Derecho material. Se trata de una garantía de ajuste o cumplimiento de la juridicidad, lo que justifica que en el procedimiento administrativo sancionador existan normas de impugnación administrativa, por la vía administrativa a través del recurso administrativo de reposición (artículo 55 LOSMA.) y jurisdiccional ante los Tribunales Ambientales (artículo 56 LOSMA.).

ii) De protección de los derechos de las personas. El procedimiento administrativo tiene una vinculación constitucional directa ${ }^{34}$. En virtud de ella los ciudadanos no pueden ser considerados objetos del procedimiento administrativo, sino que son sujetos de derechos y partes, que están vinculados en el proceso de toma de decisiones, y en el cual deben tener la posibilidad de que sus conocimientos, puntos de vista y proyectos sean tomados en cuenta. "El principio del Estado de Derecho exige -dice Maurer- no sólo una clara y previsible conformación, sino también una conformación justa" ${ }^{35}$ del procedimiento administrativo. De ello se sigue que la compatibilidad entre decisión administrativa y derechos constitucionales o fundamentales tiene un carácter bifronte: por una parte, manifestada en la decisión misma, a través del cumplimiento de los mandatos de no afectación y protección de los derechos de las personas, y por otra, dentro del propio procedimiento administrativo, es decir, en la conformación del mismo. Así los trámites previstos deben traducirse en una garantía procedimental de tales derechos. Mientras más específica y compleja es la decisión, mayores serán los requerimientos en la conformación del procedimiento administrativo ${ }^{36}$.

b) Separación de funciones de fiscalización e instrucción del procedimiento administrativo sancionador. Una de las innovaciones que plantea la LOSMA. dice relación con la potestad de auto organización que le confiere el artículo 9. En efecto, el Superintendente, en cuanto jefe del Servicio, establecerá la organización interna y determinará las denominaciones y funciones que correspondan a cada una de las unidades. Dentro de la regulación de dicha potestad, la ley fija algunas condiciones que se erigen en verdaderos límites al ejercicio de la potestad sancionadora.

En primer término, las funciones de fiscalización y de instrucción del procedimiento administrativo sancionador deben quedar a cargo de unida-

${ }^{34}$ Maurer, Hartmut, Allgemeines Verwaltungsrecht (12a edición, München, C.H. Beck, 1999), p. 465.

${ }^{35}$ Ibíd., p. 465.

${ }^{36}$ BERMÚ DEZ, Jorge, Función y tipología del procedimiento administrativo, en Acto y procedimiento administrativo. Actas de las Segundas Jornadas de Derecho Administrativo (Valparaíso, Ediciones Universitarias de Valparaíso, 2007), pp. 25-26. 
des distintas (artículo 7 inciso $2^{\circ}$ LOSMA.). Esta separación de funciones tiene su fundamento en el principio de imparcialidad (artículo 11 LBPA.), que obliga a la Administración del Estado a conducir los procedimientos administrativos con objetividad. La separación de funciones daría a entender, entonces, que una vez recibida la información obtenida producto de las labores de fiscalización, ésta podrá derivar en un procedimiento administrativo sancionador, siempre que pudiera estimarse que es constitutiva de infracción. Es decir, requiere para ello que el funcionario a cargo de la instrucción del procedimiento administrativo no se encuentre vinculado con la información remitida por el ente fiscalizador, sea éste la unidad de fiscalización de la propia SMA, o de un órgano sectorial, en virtud de un subprograma.

Por otra parte, la LOSMA. no entrega al funcionario instructor del procedimiento administrativo sancionador un poder de decisión o apreciación de la información, salvo en el caso de las denuncias, siempre que esté "revestida de seriedad y tiene mérito suficiente" (artículo 47 inciso $3^{\circ}$ LOSMA.). Por lo tanto, la instrucción de un procedimiento administrativo sancionador se rige por un principio de legalidad y no de oportunidad, con lo que -al menos al tenor de la ley- remitida la información se deberá iniciar el procedimiento administrativo sancionador.

c) Separación de funciones de instrucción del procedimiento administrativo sancionador y aplicación de la sanción. La fase de instrucción del procedimiento administrativo sancionador concluye con el dictamen del funcionario instructor, también denominado como fiscal. En el dictamen, el fiscal propone al Superintendente la absolución o sanción que a su juicio corresponda aplicar (artículo 53). La atribución de aplicar la sanción se reserva de manera privativa al Superintendente, quien estará incluso privado de la posibilidad de delegar su ejercicio [artículos 4 letra h) 7 inciso $3^{\circ}$ LOSMA.]. Nuevamente aquí la ley quiso profundizar la garantía procedimental, siendo a primera vista el principio de imparcialidad el fundamento de la separación ${ }^{37}$. Sin embargo, esta primera conclusión debe cuestionarse. La LOSMA. entrega al Superintendente amplios poderes de ordenación interna, que incluso van más allá de los que habitualmente detenta un jefe de servicio. Así por ejemplo, el Superintendente puede declarar la vacancia de un cargo de planta, por necesidades de la Superintendencia, y fundado en razones vinculadas al buen, oportuno y eficiente funcionamiento de la Superintendencia. Se trata de una facultad discrecional de difícil control externo. En consecuencia, parece dificultoso que un funcionario que ejerce labores de fiscal instructor se aparte de los criterios e instrucciones

${ }^{37}$ Reglas similares existen en el Derecho comparado, y con el mismo fundamento. Cfr. García Gómez de Mercado, F., cit. (n. 33), pp. 105-108. 
que de manera formal o informalmente le dé el Superintendente cuando pesa sobre aquél la posibilidad de la vacancia. Es por ello que la atribución privativa de la aplicación de sanciones debe entenderse como una forma de atribuir al Superintendente y sólo a él la responsabilidad en el ejercicio de tan importante poder.

d) Reglas de inhibición de ejercicio de la potestad sancionadora. La SMA tiene preeminencia en el ejercicio de la potestad sancionadora respecto de los instrumentos de gestión ambiental que la ley ha puesto bajo su fiscalización. En consecuencia, para hacer efectiva la regla del artículo 35 LOSMA. que le confiere el poder exclusivo sancionador a la Superintendencia, la ley impide que otros órganos sancionadores puedan ejercerlo. Para ello otorga un doble resguardo, ya que, por una parte una vez que se inicia un procedimiento administrativo sancionador por la SMA, ningún organismo sectorial con competencia ambiental podrá, por los mismos hechos, iniciar un procedimiento administrativo sancionatorio y tampoco podrá denunciarlos a la justicia civil, a menos que la Superintendencia se declare incompetente (artículo 59 inciso $1^{\circ}$ LOSMA.). Paralelamente, dichos organismos sectoriales con competencia ambiental estarán obligados a denunciar dichos hechos a la Superintendencia.

El segundo resguardo viene por el lado de una verdadera excepción inhibitoria, en que "En caso de que alguno de estos organismos iniciare un procedimiento respecto de materias que son competencia de la Superintendencia, ésta, de oficio o a petición de interesado, podrá solicitarle que se declare incompetente y le remita todos los antecedentes para iniciar el procedimiento respectivo" (artículo 59 inciso $2^{\circ}$ LOSMA.).

\section{Limites sustantivos.}

La SMA no puede dirigir el ejercicio de sus poderes de fiscalización y sanción respecto de cualquier materia u objeto. En este sentido, las facultades de policía se encuentran limitadas desde una triple perspectiva: por los instrumentos objeto de la fiscalización; en el carácter exclusivo de la potestad sancionadora ambiental; y en la tipificación de las infracciones ambientales.

a) Límite fundado en el tipo de instrumento que se fiscaliza. En primer término sólo podrán ser objeto de fiscalización los instrumentos de protección señalados en el artículo 2 inciso $1^{\circ}$ LOSMA. Este es el caso de las resoluciones de calificación ambiental, medidas de planes de prevención, y descontaminación, normas de calidad y emisión; así como de los planes de manejo; como también respecto de "todos aquellos otros instrumentos de carácter ambiental que establezca la ley".

Como se ha dicho, el carácter exclusivo de las competencias no implica 
la pérdida de facultades fiscalizadoras por parte de los organismos sectoriales, sino que éstas quedan supeditadas a la SMA. En efecto, como se señaló, ellas deberán desarrollarse en el marco de los programas y subprogramas elaborados por parte de la Superintendencia, conforme a los artículos 16 y siguientes LOSMA.

La fiscalización sobre los instrumentos ambientales corresponde a una competencia que la SMA puede ejercer directamente y a diferencia de lo que ocurría bajo la sola vigencia de la LBGMA., la fiscalización de las normas y planes ya no queda condicionada a su incorporación dentro de resoluciones de calificación ambiental, pudiendo ejercerse de manera independiente.

Sin embargo, desde una perspectiva negativa, o como verdadero límite a los poderes de fiscalización, se debe concluir que la SMA no tiene un poder de fiscalización ambiental general, sino sólo acotado a los mencionados instrumentos. Es decir, no toda materia comprendida en la protección ambiental es fiscalizada, sino sólo aquella comprendía en los instrumentos. Evidentemente, no queda duda respecto de su competencia respecto de: RCA; medidas planes de prevención y descontaminación; normas de calidad y emisión; y planes de manejo. No obstante, un punto dudoso se plantea en la aparente consagración legal de una enumeración abierta de instrumentos fiscalizables, En efecto, el citado artículo 2 inciso $1^{\circ}$ LOSMA. cierra la enumeración disponiendo que la SMA fiscaliza "todos aquellos otros instrumentos de carácter ambiental que establezca la ley". Esta expresión puede dar a entender, desde una perspectiva amplia, que la SMA fiscaliza todo instrumento ambiental creado en una norma jurídica, lo que llevaría a entender que su competencia es íntegra o global, cuando se trata de fiscalización ambiental. Contrariamente, implica que sólo podrá fiscalizar aquellos instrumentos en que expresamente la ley hubiere señalado que corresponden a la Superintendencia. A favor de esta interpretación restrictiva juega un argumento sistemático, ya que el artículo 3 letra t) le entrega a la SMA la fiscalización del cumplimiento de las demás normas e instrumentos de carácter ambiental, que no estén bajo el control y fiscalización de otros órganos del Estado. Se trata de una cláusula de cierre del sistema de fiscalización ambiental que procura que no existan instrumentos de gestión ambiental sin fiscalización y sanción. Por ello, en los casos que se encuentren fuera del artículo 2 LOSMA., lo lógico será que un órgano sectorial lleve a cabo la fiscalización, lo contrario, es decir, que el instrumento de gestión ambiental no tuviere atribuido un órgano fiscalizador, constituiría una anomalía del sistema administrativo, que se suple con el antes citado artículo 3 letra t).

Finalmente, y como se desprenderá del apartado $c$ ) siguiente, es probable que esta última sea la interpretación más plausible, si se considera la tipificación de infracciones administrativas ambientales. 
b) Límite fundado en el carácter exclusivo de la potestad sancionadora a mbiental. Junto con las competencias fiscalizadoras, las atribuciones para la imposición de sanciones constituyen el segundo título de intervención característico de las Superintendencias. Este es también en el caso de la SMA. Sin embargo, a diferencia de las facultades de fiscalización, el ejercicio de las competencias sancionadoras no ha sido diversificado en múltiples organismos. Así se deriva del artículo 35 LOSMA., que dispone: "corresponderá exclusivamente a la Superintendencia del Medio Ambiente el ejercicio de la potestad sancionadora respecto de las siguientes infracciones". Por ello, si la fiscalización admite una distinción entre competencias exclusivas, ejercidas directamente por la SMA, y no exclusivas, ejercidas por órganos sectoriales, debemos concluir que, por el contrario, las facultades sancionadoras son siempre exclusivas, sin perjuicio del carácter residual del artículo 35 letra n) LOSMA., al permitir sancionar infracciones ambientales no establecidas bajo la competencia de otro organismo ${ }^{38}$.

La atribución de competencias exclusivas supera las críticas de la regulación anterior, dada la ambigüedad del antiguo artículo 64 LBGMA., que si bien precisaba facultades de fiscalización por parte de los organismos sectoriales, carecía de claridad respecto de sus competencias sancionadoras. La jurisprudencia administrativa se inclinó invariablemente por la prevalencia de la competencia ambiental ${ }^{39}$. Esta prevalencia fue posteriormente armonizada mediante diferentes oficios de los órganos concurrentes, intentando establecer limitaciones de competencias, a fin de evitar los cúmulos sancionadores ${ }^{40}$. La reforma introducida por la Ley No 20.417 establece un criterio unificador en materia sancionadora, la que, como se ha dicho, corres-

${ }^{38}$ Sin perjuicio de la redacción del precepto, la disposición debe entenderse como una atribución de competencia residual. Por ello, debió especificar la ausencia de competencias por parte de otro órgano y no el no establecimiento de una sanción. Toda disposición no anudada a un castigo no puede interpretarse en términos infraccionarios, como tampoco es posible concluir que esta disposición tipifique una infracción general respecto de un "incumplimiento cualquiera de toda otra norma de carácter ambiental". Una interpretación en este sentido excedería los términos restrictivos del ius puniendi estatal, como también el sentido común.

${ }^{39}$ Dictámenes No 981, de 2003; y N³9.696, de 2005, de la Contraloría General de la República.

${ }^{40}$ Con posterioridad al Dictamen No 981, de 2003, de la Contraloría General de la República y los Ministerios Secretaría General de la Presidencia y de Salud emitieron el ordinario No 449 de 26 de abril de 2005. En él se detallaban aspectos de la fiscalización realizada por los organismos, describiendo formas de delimitar las competencias de los servicios. En general, el criterio pretendía distinguir las exigencias y condiciones que sirvieron de base a la calificación ambiental favorable, quedando bajo la esfera de competencias ambientales. En los restantes casos, subsisten las potestades de la Autoridad Sanitaria conforme al Código Sanitario. 
ponde de forma exclusiva a la SMA. No obstante lo anterior, el alcance de la competencia sectorial no siempre es claro y, asimismo, puede entenderse en contradicción con otras disposiciones de la ley, como ocurre respecto de la mantención de las facultades fiscalizadoras y sancionadoras por parte de la Superintendencia de Servicios Sanitarios, en relación al cumplimiento de las normas sobre prestación de los servicios públicos de agua potable y alcantarillado que realicen las concesionarias (artículo 61 LOSMA.). En este punto, la concurrencia de competencias ya había sido resuelta por parte de la Contraloría General de la República, debilitando la uniformidad del criterio de fiscalización ambiental, al distinguir aspectos diversos, como la vinculación existente entre la fiscalización y el destinatario ${ }^{41}$.

c) Límite fundado en la tipificación de infracciones ambientales. La tipificación de infracciones ambientales en el artículo 35 LOSMA. presenta como primer carácter evidente poseer rango legal, lo que no siempre ocurre en el ordenamiento jurídico administrativo sancionador ${ }^{42}$. Al analizar la tipificación de las infracciones ambientales, es posible concluir que ésta es más amplia que la potestad sancionatoria que emana de los instrumentos de gestión ambiental, objeto de la fiscalización. Lo anterior se justifica en cuanto los ilícitos que exceden este marco, son de carácter instrumental. Ellos están listados en la tercera columna de la Tabla 1. Por su parte, la tipificación y sanción a las entidades de inspección acreditadas (fila 3 de la Tabla 1), se justifica por la especial vinculación en que se encuentran éstas, y por el ejercicio de verdaderos poderes jurídico-públicos que le corresponde.

${ }^{41}$ En este sentido, el Dictamen No 25.248 de la Contraloría General de la República, de mayo de 2012, señala: "a la Superintendencia del Medio Ambiente le corresponde la fiscalización y sanción de las normas relacionadas con las descargas de residuos líquidos industriales, y a la de Servicios Sanitarios, el control y sanción de los residuos líquidos industriales que se encuentren vinculados a las prestaciones o servicios de las empresas sanitarias', para delimitar la competencia de cada uno de dichos organismos públicos, es necesario determinar los casos en que se produce tal vinculación con los anotados residuos líquidos".

${ }^{42}$ Desde una perspectiva crítica a la remisión al reglamento, véase: Soто KLOss, Eduardo, La potestad sancionadora de la Administración ¿se adecua a la Constitución?, en Sanciones administrativas y derechos fundamentales: regulación y nuevo intervencionismo (Santiago, Universidad Santo Tomás, 2005), pp. 48-49. 


\section{Clasificación de infracciones administrativas ambientales}

Tabla No 1

\begin{tabular}{|c|c|c|}
\hline $\begin{array}{l}\text { Infracciones según } \\
\text { el destinatario }\end{array}$ & $\begin{array}{l}\text { Incumplimiento de con- } \\
\text { diciones de resoluciones }\end{array}$ & $\begin{array}{l}\text { Actuar sin autorización o } \\
\text { contraviniendo una orden de } \\
\text { la SMA }\end{array}$ \\
\hline $\begin{array}{l}\text { Infracciones de los } \\
\text { destinatarios de la fisca- } \\
\text { lización ambiental }\end{array}$ & $\begin{array}{l}\text { a) El incumplimiento } \\
\text { de las condiciones, normas } \\
\text { y medidas establecidas en las } \\
\text { resoluciones de calificación } \\
\text { ambiental. } \\
\text { c) El incumplimiento } \\
\text { de las medidas e instrumen- } \\
\text { tos previstos en los Planes } \\
\text { de Prevención y, o de Des- } \\
\text { contaminación, normas de } \\
\text { calidad y emisión, cuando } \\
\text { corresponda. } \\
\text { i) El incumplimiento de } \\
\text { los planes de recuperación, } \\
\text { conservación y gestión de } \\
\text { especies establecidos en la Ley } \\
\text { No } 19.300 \text {. } \\
\text { k) El incumplimiento de } \\
\text { los planes de manejo a que se } \\
\text { refiere la Ley No } 19.300 . \\
\text { n) El incumplimiento } \\
\text { cualquiera de toda otra nor- } \\
\text { ma de carácter ambiental } \\
\text { que no tenga establecida una } \\
\text { sanción específica. }\end{array}$ & $\begin{array}{l}\text { b) La ejecución de proyectos } \\
\text { y el desarrollo de actividades para } \\
\text { los que la ley exige Resolución } \\
\text { de Calificación Ambiental, sin } \\
\text { contar con ella. Asimismo, el in- } \\
\text { cumplimiento del requerimiento } \\
\text { efectuado por la Superintendencia } \\
\text { según lo previsto en las letras i), j), } \\
\text { y k) del artículo } 3^{\circ} \text {. } \\
\text { e) El incumplimiento de las } \\
\text { normas e instrucciones generales } \\
\text { que la Superintendencia imparta } \\
\text { en ejercicio de las atribuciones que } \\
\text { le confiere esta ley. } \\
\text { f) Incumplir las medidas } \\
\text { adoptadas por la superintendencia } \\
\text { en virtud de lo dispuesto en las } \\
\text { letras g) y h) del artículo } 3^{\circ} \text {. } \\
\text { g) El incumplimiento de las } \\
\text { leyes, reglamentos y demás normas } \\
\text { relacionadas con las descargas de } \\
\text { residuos líquidos industriales. } \\
\text { h) El incumplimiento de } \\
\text { las Normas de Emisión, cuando } \\
\text { corresponda. } \\
\text { j) El incumplimiento de los } \\
\text { requerimientos de información } \\
\text { que la Superintendencia dirija a } \\
\text { los sujetos fiscalizados, de confor- } \\
\text { midad a esta ley. } \\
\text { 1) El incumplimiento de las } \\
\text { obligaciones derivadas de las me- } \\
\text { didas provisionales previstas en el } \\
\text { artículo } 48 \text {. } \\
\text { m) El incumplimiento de } \\
\text { la obligación de informar de los } \\
\text { responsables de fuentes emisoras, } \\
\text { para la elaboración del registro al } \\
\text { cual hace mención la letra p) del } \\
\text { artículo } 70 \text { de la ley No } 19.300 .\end{array}$ \\
\hline $\begin{array}{l}\text { Infracciones de las } \\
\text { entidades de inspección } \\
\text { acreditadas }\end{array}$ & \multicolumn{2}{|c|}{$\begin{array}{l}\text { d) El incumplimiento por parte de entidades técnicas acredi- } \\
\text { tadas por la Superintendencia, de los términos y condiciones bajo } \\
\text { las cuales se les haya otorgado la autorización, o de las obligaciones } \\
\text { que esta ley les imponga. }\end{array}$} \\
\hline
\end{tabular}




\section{Conclusiones}

Desde el momento en que la protección ambiental se transforma en una función estatal, y un deber concreto de actuación, se pone a su disposición todo el instrumentario administrativo, lo que incluye el ejercicio de la potestad sancionadora de la Administración. Esto resulta válido respecto de cualquier sujeto particular y no sólo en función de aquéllos que se vinculan más directamente con la Administración, atendido que tanto a los ciudadanos como a las empresas corresponde jugar un rol en la protección ambiental.

La profundización de la conciencia ambiental en la sociedad explica, entre otras razones, la reforma y modernización de la Administración Pública ambiental. Este cambio en la llamada institucionalidad ambiental trajo como una de sus principales innovaciones la creación de un nuevo órgano que concentra las facultades de fiscalización y sanción ambiental. La existencia de una Superintendencia del Medio Ambiente actualiza respecto de esta institución una doble discusión. En primer término, tuvo que hacerse cargo de la posición refractaria de amplios sectores ante la utilización del instrumento administrativo sancionador como herramienta eficaz para la protección del medio ambiente. Superado el obstáculo, se planteó la aplicación de las limitaciones que reconoce el Derecho Administrativo Sancionador General.

A pesar de formar parte del poder sancionador administrativo, el ejercicio de dicha potestad por parte de la SMA reconoce unos límites específicos, que no se delinearon tan claramente por el legislador respecto de otros órganos públicos sancionadores. En efecto, la potestad sancionadora ambiental reconoce límites orgánicos, procedimentales y sustantivos. Tales límites constituyen un freno o contrapeso al ejercicio de la potestad sancionadora por parte de la Superintendencia. Sin embargo, lo que en ocasiones se dispone como una manifestación de preeminencia del ejercicio del poder sancionador por la autoridad ambiental, visto desde la perspectiva de los órganos sectoriales, constituye para ellos también una limitación que se irradia al ejercicio de sus facultades.

En definitiva, la potestad sancionadora ambiental fue delineada como un poder fuerte que efectivamente cumpla un rol de prevención general, pero dotado de límites administrativos, que al menos en el papel parecen ser manifestación de una garantía y equilibrio para el particular. Sin embargo, sólo el ejercicio práctico de dicho poder nos dará una idea de la forma en que, para el caso concreto, el administrador entiende tales límites. 


\section{BiBLIOGRAFÍA}

Astorga, Eduardo, Derecho ambiental chileno. Parte general (Santiago, LexisNexis, 2006).

BERMÚDEZ, Jorge, El acceso a la información pública y la justicia ambiental, en Revista de Derecho de la Pontificia Universidad Católica de Valparaiso, 34 (Valparaíso, primer semestre de 2010).

Bermú DEZ, Jorge, Función y tipología del procedimiento administrativo, en Acto y procedimiento administrativo. Actas de las Segundas Jornadas de Derecho Administrativo (Valparaíso, Ediciones Universitarias de Valparaíso, 2007).

BERMúDEZ, Jorge, Fundamentos de Derecho Ambiental (Valparaíso, Ediciones Universitarias de Valparaíso, 2007).

Breuer, Rüdiger, Umweltschutzrecht, en Schmidt-Abmann, Eberhard (editor), Besonderes Verwaltungsrecht (11 a edición, Berlín, 1999).

Camacho Cepeda, Gladys, La problemática de la potestad normativa de las superintendencias, en Actas de las XXXIV Jornadas de Derecho Público (Santiago, Lexis Nexis, 2005).

Cano, Tomás, Derecho administrativo sancionador, en Revista Española de Derecho Constitucional, 43 (enero-abril de 1995).

Cordero Vega, Luis, Evaluando el Sistema de Fiscalización Ambiental chileno. Desarrollo sustentable: gobernanza y Derecho, en Actas de las Cuartas Jornadas de Derecho Ambiental (Santiago, 2008).

CoRDERo, Eduardo, El Derecho administrativo sancionador y su relación con el Derecho penal, en Revista de Derecho, Universidad Austral de Valdivia, 25 (diciembre de 2012) 2 .

GARcía Gómez de MerCAdo, Francisco, Sanciones administrativas, garantías, derechos y recursos del presunto responsable (Granada, Comares, 2004).

García, José Francisco, ¿Inflación de superintendencias? Un diagnóstico crítico desde el derecho regulatorio, en Revista Actualidad Jurídica, 10 (enero de 2009) I.

Garrido Falla, Fernando, Los medios de policia y la teoría de las sanciones administrativas, en Revista de Administración Pública, 28 (1959).

Gorke, Martin, Kann die biologische Vielfalt gerettet werden und wie wäre das zu bewerkstelligen? (Baden-Baden, Nomos, 2002).

Guiloff, Matías, Reforma a la institucionalidad ambiental: un análisis desde el diseño institucional, en Reforma a la institucionalidad ambiental: antecedentes y fundamentos, programa de derecho y politica ambiental (Santiago, Ediciones de la Universidad Diego Portales, 2010).

Kilian, Michael, Finanzierung des Umweltschutzes, en Rengeling, Hans-Werner (editor), Handbuch zum europäischen und deutschen Umweltrecht (Köln, Carl Heymanns, 1998).

Lozano, Blanca, La responsabilidad de la persona jurídica en el ámbito sancionador administrativo (A propósito de la STC 246/1991, de 19 de diciembre), en Revista de Administración Pública, 129 (septiembre-diciembre de 1992).

Maurer, Hartmut, Allgemeines Verwaltungsrecht (12a edición, München, C.H. Beck, 1999). 
Mondaca, Alberto, Significado y técnica jurídica de la policía administrativa, en Revista de Administración Pública, 28 (1959).

Quintero, Gonzalo, La autotutela, los limites alpoder sancionador de la Administración Pública y los principios inspiradores del Derecho penal, en Revista de Administración Pública, 126 (septiembre-diciembre de 1991).

Rebollo, Manuel, y otros, Panorama del Derecho administrativo sancionador en España, en Revista Estudios Socio-Jurídicos, 7 (Bogotá, enero-junio de 2005) 1.

Rojas, Christian, Los organismos autónomos y la Administración del Estado, en Estudios sobre la Ley Orgánica Constitucional de Bases Generales de la Administración del Estado. Actas de las Terceras Jornadas de Derecho Administrativo (Antofagasta).

Santamaría Pastor, Alfonso, Principios de Derecho Administrativo (Madrid, Centro de Estudios Ramón Areces, 2002), II.

Schmidt-Assmann, Eberhard, Das allgemeine Verwaltungsrecht als Ordnungsidee (2a edición, Berlin - Heidelberg, Springer, 2006).

SEPÚlvedA, Doris, Invalidación sobreviniente: El caso de la Resolución de Calificación Ambiental (Santiago, Abeledo Perrot - Thomson Reuters, 2012).

Sото KLoss, Eduardo, La potestad sancionadora de la Administración ise adecua a la Constitución?, en Sanciones administrativas y derechos fundamentales: regulación y nuevo intervencionismo (Santiago, Universidad Santo Tomás, 2005).

SuAY, José, El Derecho administrativo sancionador: Perspectivas de reforma, en Revista de Administración Pública, 109 (enero-abril de 1986).

Velasco, Francisco, Las cláusulas accesorias del acto administrativo (Madrid, Tecnos, 1996). 
